\title{
Sound Attenuation of Membranes Loaded with Square Frame-Shaped Masses
}

\author{
J. S. Chen ${ }^{1}$ and D. W. Kao ${ }^{2}$ \\ ${ }^{1}$ Department of Engineering Science, National Cheng Kung University, No. 1, University Road, Tainan City 701, Taiwan \\ ${ }^{2}$ Missile and Rocket Systems Research Division, National Chung-Shan Institute of Science and Technology, \\ No. 481, Sec. Jia'an, Zhongzheng Road, Longtan District, Taoyuan City 32546, Taiwan
}

Correspondence should be addressed to J. S. Chen; jschen273@mail.ncku.edu.tw

Received 4 February 2016; Accepted 5 April 2016

Academic Editor: Gregory Chagnon

Copyright (C) 2016 J. S. Chen and D. W. Kao. This is an open access article distributed under the Creative Commons Attribution License, which permits unrestricted use, distribution, and reproduction in any medium, provided the original work is properly cited.

\begin{abstract}
This study examines sound transmission of thin membranes with square frame-shaped masses. Numerical results indicate that multiple transmission loss peaks can be generated by adding more frame mass inclusions. The number and the location of the peaks are controlled by the number of frames, the frame distribution, and the frame width. Near the transmission loss peak frequencies, the dynamic effective mass density turns from positive to negative. The validity of the present model has been verified by comparing the analytical results with FE results. Two types of cell arrangements are also considered in this study, namely, cells in series and cells in array. It is seen that either the stacked or array configurations can produce better sound attenuation than single-celled structures. Moreover, the frequency band where sound wave is blocked can be broadened by stacking more layers with different mass magnitudes. Furthermore, additional frequency bands due to the periodicity of the structure are found in the stacked configurations.
\end{abstract}

\section{Introduction}

Broadband noise reduction has been investigated over decades. Many researchers have demonstrated that the addition of foams or fiber batting can effectively attenuate sound at certain frequencies $[1,2]$. Impedance mismatch of gap layer and the use of microperforated panels/mass inclusions also have been feasible tools for enhancing sound insulation [3-6]. Recently, negative dynamic mass density structures become popular candidates for attenuating elastic waves [7-12] or acoustic waves [13-22] over a certain band of frequencies. For the attenuation of elastic waves, the first proposed promising candidate was a one-dimensional mass-in-mass system usually comprised of a host mass connected to an auxiliary mass by massless and elastic springs. This class of metamaterials is able to create a resonant-type bandgap where waves cannot propagate freely. To acquire multiple bandgaps at desired frequency range, two-dimensional designs of metamaterials, such as metacomposites [11] and multiscale mass-in-mass systems [12], were subsequently introduced. For sound isolation, the basic unit of the pioneering composite is usually comprised of an elastic membrane and a centrally loaded mass. The desired frequency band where sound waves cannot propagate can be achieved by tailoring the mass weight. To eliminate sounds with multiple frequencies, multicelled structures were also proposed [16-18]. Different magnitudes of mass attached to each of the cells in the array can create a multipeak transmission loss profile. In addition to using four-celled array, geometric variation of inclusions is an alternative solution to effectively increase frequency bandwidth and produce multiple transmission loss peaks [19]. Their findings show that the characteristics of transmission loss profile can be manipulated by the number of rings and the distribution of mass. Phononic crystals constituted by periodical repetition of inclusions in a background material also can create frequency gaps which are known as Bragg bandgaps and usually occurred at high frequencies [23, 24]. Because Bragg-type bandgaps are not practice for filtering low-frequency waves, a new design of phononic crystals with locally resonant structures, which can generate flexible resonant-type bandgaps, was developed [25-28]. By altering the properties of the resonant units, the opening and closing 
of the low-frequency gaps and the gap frequency ranges can be controlled or shifted. Other types of acoustic metamaterials, such as an array of side holes on a tube or an array of thin elastic membranes, have demonstrated their potential capability of filtering low-frequency sound $[29,30]$. Those structures exhibit either a negative effective modulus or a negative effective density in a certain frequency range where acoustic waves produced by the excitation are completely blocked.

Sandwich panels containing lightweight honeycomb core are widely used in aircraft and satellite launch vehicles [6, 31]. Although sandwich panels have good benefit of static strength, they are relatively weak in sound insulation. To improve their performance in acoustic absorption, the use of the aforementioned efficient tools becomes necessary. Since the honeycomb core usually has a shape of square form or hexagon form, membrane-frame acoustic metamaterials might be more suitable selections. In this study, the acoustic response of square membranes with multiple frame masses is presented. The governing equation of the proposed vibroacoustic problem is obtained by using the energy method. Parameter studies including frame mass density, frame location, and frame width on transmission loss are emphasized. Two types of structure arrangements, a series-type structure and an array-type structure, are also introduced and compared with single-celled structures. The dynamic effective mass density of the system is also studied.

\section{Model}

Figure 1 shows a novel design of a basic unit that can be used to construct a membrane-type locally resonant acoustic metamaterial. This structure unit consists of a thin tensioned membrane with one/multiple frame mass (mass $m$ ) embedded in the membrane. Consider a plane sound wave of frequency $\omega$ and amplitude $A$ normally incident upon the membrane from the region $z<0$. Here we assume that the bending stiffness of the membrane is overlooked and the frame mass does not hinder the bending of the membrane segment.

The governing equations for the present structure can be derived by using Hamilton's principle [32] which states

$$
\int_{t_{1}}^{t_{2}} \delta(T-(U+V)) d t=0
$$

where $U, T, V$ are deformation, kinetic, and potential energy, respectively. We have

$$
\begin{aligned}
T & =\frac{1}{2} \int_{0}^{b} \int_{0}^{a}\left[\rho_{\text {membrane }}+\sum_{i=1}^{Q}\left(\rho_{\text {mass }}\right)_{i}\left(\hbar_{i}-\hbar_{i}^{\prime}\right)\right] \\
& \cdot\left(\frac{\partial w}{\partial t}\right)^{2} d x d y,
\end{aligned}
$$

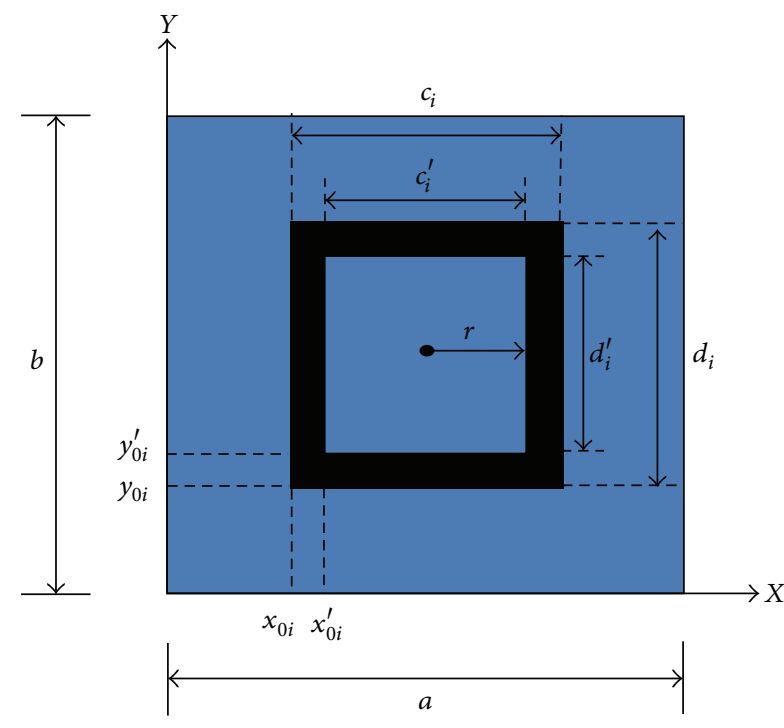

FIGURE 1: A sketch of membrane-frame structure.

$$
\begin{aligned}
& U=\frac{1}{2} \int_{0}^{b} \int_{0}^{a} F\left[\left(\frac{\partial w}{\partial x}\right)^{2}+\left(\frac{\partial w}{\partial y}\right)^{2}\right] d x d y, \\
& V=-\int_{0}^{b} \int_{0}^{a}\left[P^{-}-P^{+}\right] w d x d y
\end{aligned}
$$

in which $a, b, \rho_{\text {membrane }}$ denote the length, width, and density per unit area of the membrane, $\left(\rho_{\text {mass }}\right)_{i}$ denotes the density per unit area of the $i$ th frame mass, $Q$ is the number of frame masses, $F$ is the intensity of tension, $P^{-}$and $P^{+}$are acoustic pressure field in the negative and positive $z$ direction, $w=$ $w(x, y, t)$ is the transverse displacement in the $z$ direction of the membrane-frame structure, and $\hbar_{i}-\hbar_{i}^{\prime}$ represents the area of the $i$ th frame mass as shown as follows:

$$
\begin{aligned}
\hbar_{i}-\hbar_{i}^{\prime}= & {\left[H\left(x-x_{0 i}\right)-H\left(x-x_{0 i}-c_{i}\right)\right] } \\
& \cdot\left[H\left(y-y_{0 i}\right)-H\left(y-y_{0 i}-d_{i}\right)\right] \\
& -\left[H\left(x-x_{0 i}^{\prime}\right)-H\left(x-x_{0 i}^{\prime}-c_{i}^{\prime}\right)\right] \\
& \cdot\left[H\left(y-y_{0 i}^{\prime}\right)-H\left(y-y_{0 i}^{\prime}-d_{i}^{\prime}\right)\right],
\end{aligned}
$$

where $H$ is Heaviside function. Substituting (2) into (1) gives the equation of motion; namely,

$$
\begin{aligned}
& \rho_{\text {membrane }} \frac{\partial^{2} w}{\partial t^{2}}+\sum_{i=1}^{Q}\left(\rho_{\text {mass }}\right)_{i}\left(\hbar_{i}-\hbar_{i}^{\prime}\right) \frac{\partial^{2} w}{\partial t^{2}}-F \nabla^{2} w \\
& =P^{-}-P^{+}
\end{aligned}
$$

where $P^{-}-P^{+}$is the pressure difference between the left-hand side and right-hand side of the membrane at $z=0$. It can be simply expressed as [33]

$$
P^{-}-P^{+}=2 A e^{j \omega t}-2 \rho_{\text {air }} c_{\text {air }} \frac{\partial w}{\partial t},
$$


in which $A$ is plane sound wave pressure amplitude, $\omega$ is the wave frequency, $\rho_{\text {air }}$ is the density of the air, and $c_{\text {air }}$ is the speed of sound. To apply Galerkin discretization procedure [34] to (4), the transverse displacement function $w$ is expressed as

$$
w(x, y, t)=\sum_{n=1}^{N} W_{n}(x, y) u_{n}(t)
$$

where $W_{n}(x, y)$ is the mode function and $u_{n}(t)$ is the harmonic time function excited by the acoustic load; that is,

$$
u_{n}(t)=\widehat{u}_{n} e^{j \omega t}
$$

The mode shape of the membrane simply supported on all four sides can be expressed as [35]

$$
W_{n}(x, y)=\sin \frac{k \pi x}{a} \sin \frac{l \pi y}{b} \quad k, l=1,2, \ldots
$$

Substituting (6) and (7) into (4), multiplying each term by $W_{m}(x, y)$, and integrating all terms in the equation over the domain $(0 \leq x \leq a, 0 \leq y \leq b)$ give

$$
\begin{aligned}
& -\omega^{2}\left(\rho_{\text {membrane }} \int_{0}^{b} \int_{0}^{a} W_{m} \sum_{n=1}^{N} W_{n} d x d y\right) \widehat{u}_{m} \\
& -\omega^{2} \sum_{i=1}^{Q}\left(\rho_{\text {mass }}\right)_{i} \sum_{n=1}^{N}\left(\left[\int_{y_{0 i}}^{y_{0 i}+d_{i}} \int_{x_{0 i}}^{x_{0 i}+c_{i}} W_{m} W_{n} d x d y\right.\right. \\
& \left.\left.-\int_{y_{0 i}^{\prime}}^{y_{0 i}^{\prime}+d_{i}^{\prime}} \int_{x_{0 i}^{\prime}}^{x_{0 i}^{\prime}+c_{i}^{\prime}} W_{m} W_{n} d x d y\right]\right) \widehat{u}_{n} \\
& +j \omega\left(2 \rho_{\text {air }} c_{\text {air }} \int_{0}^{b} \int_{0}^{a} W_{m} \sum_{n=1}^{N} W_{n} d x d y\right) \widehat{u}_{m} \\
& +\left(-F \int_{0}^{b} \int_{0}^{a} W_{m} \nabla^{2} \sum_{n=1}^{N} W_{n} d x d y\right) \widehat{u}_{m} \\
& =2 A\left(\int_{0}^{b} \int_{0}^{a} W_{m} d x d y\right) .
\end{aligned}
$$

Let

$$
\begin{gathered}
M_{m}=\rho_{\text {membrane }} \int_{0}^{b} \int_{0}^{a} W_{m} \sum_{n=1}^{N} W_{n} d x d y \\
\left(S_{m n}\right)_{i}=\left[\left(\int_{y_{0 i}}^{y_{0 i}+d_{i}} \int_{x_{0 i}}^{x_{0 i}+c_{i}} W_{m} W_{n} d x d y\right)\right. \\
\left.-\left(\int_{y_{0 i}^{\prime}}^{y_{0 i}^{\prime}+d_{i}^{\prime}} \int_{x_{0 i}^{\prime}}^{x_{0 i}^{\prime}+c_{i}^{\prime}} W_{m} W_{n} d x d y\right)\right]
\end{gathered}
$$

$$
\begin{aligned}
& C_{m}=2 \rho_{\text {air }} c_{\text {air }} \int_{0}^{b} \int_{0}^{a} W_{m} \sum_{n=1}^{N} W_{n} d x d y, \\
& K_{m}=-F \int_{0}^{b} \int_{0}^{a} W_{m} \nabla^{2} \sum_{n=1}^{N} W_{n} d x d y, \\
& D_{m}=\int_{0}^{b} \int_{0}^{a} W_{m} d x d y .
\end{aligned}
$$

Equation (9) can be simplified as

$$
\begin{aligned}
& -\omega^{2}\left\{M_{m} \widehat{u}_{m}+\sum_{i=1}^{Q}\left[\left(\rho_{\text {mass }}\right)_{i} \sum_{n=1}^{N}\left(S_{m n}\right)_{i} \widehat{u}_{n}\right]\right\} \\
& +j \omega C_{m} \widehat{u}_{m}+K_{m} \widehat{u}_{m}=2 A D_{m} \\
& \quad(m=1,2, \ldots, N) .
\end{aligned}
$$

Rewriting (11) in the matrix form gives

$$
\left\{-\omega^{2}\{[\mathbf{M}]+[\mathbf{R}]\}+j \omega[\mathbf{C}]+[\mathbf{K}]\right\}\{\widehat{\mathbf{u}}\}=2 A\{\mathbf{D}\},
$$

where $[\mathbf{M}],[\mathbf{K}]$, and $[\mathbf{C}]$ are $N \times N$ diagonal matrices, $\{\mathbf{D}\}$, $\{\mathbf{W}\}$, and $\{\widehat{\mathbf{u}}\}$ are $N \times 1$ matrices, and $\{\mathbf{R}\}$ is also $N \times N$ matrix and has a form as follows:

$$
[\mathbf{R}]=\sum_{i=1}^{Q}\left(\rho_{\text {mass }}\right)_{i}\left[\begin{array}{cccc}
\left(S_{11}\right)_{i} & \left(S_{12}\right)_{i} & \cdots & \left(S_{1 N}\right)_{i} \\
\left(S_{12}\right)_{i} & \left(S_{22}\right)_{i} & \cdots & \left(S_{2 N}\right)_{i} \\
\vdots & \vdots & \ddots & \vdots \\
\left(S_{N 1}\right)_{i} & \left(S_{N 2}\right)_{i} & \cdots & \left(S_{N N}\right)_{i}
\end{array}\right] .
$$

The solution of displacement amplitude $\widehat{w}(x, y)$ also can be written in the matrix form as

$$
\widehat{w}(x, y)=\sum_{n=1}^{N} W_{n}(x, y) \widehat{u}_{n}=\{\mathbf{W}\}^{\mathrm{T}}\{\widehat{\mathbf{u}}\},
$$

where $\{\widehat{\mathbf{u}}\}$ is acquired from (12). Hence we can get the sound power amplitude transmission coefficient $\tau$ defined as the ratio of transmitted to incident intensities [33]:

$$
\tau=\left|\frac{\rho_{\mathrm{air}} c_{\mathrm{air}}\langle\widehat{v}\rangle}{A}\right|^{2},
$$

where $\langle\widehat{v}\rangle$ is the average velocity amplitude of the entire membrane. Then the sound transmission loss (TL) can be obtained by

$$
\mathrm{TL}=10 \log _{10}\left(\frac{1}{\tau}\right) .
$$

To treat the whole structure as a homogeneous membrane, the dynamic effective mass density is introduced and acquired by

$$
\rho_{\text {eff }}=\frac{\left(\left\langle\hat{p}_{t}\right\rangle-\left\langle\hat{p}_{i}\right\rangle\right)}{\langle\widehat{a}\rangle},
$$

where $\langle\hat{a}\rangle$ is the averaged out-of-plane acceleration of the structure, which is normal to the membrane surface at rest; $\left\langle\widehat{p}_{t}\right\rangle-\left\langle\widehat{p}_{i}\right\rangle$ is the averaged pressure difference between the transmitted wave and the incident wave. 
TABLE 1: Physical properties of membrane material [16].

\begin{tabular}{lc}
\hline Property & Polyetherimide $(\mathrm{PEI})$ \\
\hline Mass density $\left(\mathrm{kg} / \mathrm{m}^{3}\right)$ & 1200 \\
Young's modulus $(\mathrm{Pa})$ & $3.6 \times 10^{9}$ \\
Poisson ratio & 0.36 \\
Thickness $(\mathrm{mm})$ & 0.076 \\
Length $(\mathrm{mm})$ & 27.4 \\
Tension $(\mathrm{Pa})$ & $6.4 \times 10^{6}$ \\
\hline
\end{tabular}

\section{Numerical Results}

Consider a single-celled structure comprised of a square membrane with an embedded frame mass as shown in Figure 1 . The characteristics of sound transmission of the present structure were evaluated using the analytical approach and finite element method. In the finite element analysis, the commercial code COMSOL Multiphysics is used to capture the dynamic behavior of the membrane-frame structure. All the physical properties of the membrane material are displayed in Table 1. Table 2 lists the properties (mass, width, and location) of frame-shaped inclusions embedded in the membrane.

Figure 2 shows the transmission loss of four illustrative examples. Analytical results are obtained by using (16); FE results are calculated from the ratio of the incident power to the transmitted power. It is found that the agreement between analytical and finite element methods is quite good. In Figures 2(a) and 2(b), only one TL peak and two TL dips occur while in Figures 2(c) and 2(d), two TL peaks and three TL dips are found. It is evident that the addition of frame masses can produce more TL peaks. The TL dips correspond to resonance behavior where sound transmission reaches a maximum, while the TL peaks correspond to antiresonance where sound transmission is minimized.

Figures 3(a)-3(d) exhibit the dynamic effective mass density of four membrane structures (Model I, Model II, Model III, and Model IV), respectively, as a function of the frequency. Analytical results are acquired by using (17); FE results are obtained by dividing the average pressure on the membrane surface by the average membrane acceleration. It is seen that near the TL peak frequencies, negative effective mass occurs. Observation of the results shown in Figures 3(c) and $3(\mathrm{~d})$ presents that the addition of a frame mass leads to an additional jump where the effective mass turns from positive to negative.

Figure 4 illustrates the effect of the material and geometrical properties of the embedded frame on the TL plot of the membrane-frame structure. The results of Figure 4(a) indicate that the first TL peak and valley have a strong dependency on the magnitude of the frame mass. With an increase of the frame mass, the first peak and valley move toward low-frequency region. As the frame width increases, the first TL peak and valley slightly shift to higher frequencies (Figure 4(b)). The first TL valley is from the frame mass and membrane vibrating coherently while the second TL valley is from the membrane vibration with the motionless frame mass. The first TL peak is viewed as the result of superposition of two resonant eigenmodes and has a strong dependency on the frame mass. Hence, as shown in Figure 4(a), the change in frame mass magnitude greatly influences the first TL peak and valley frequencies but has no effect on the second TL valley. On the contrary, with the same mass magnitude and frame location, the change in frame width significantly influences the second TL valley but has a relatively small impact on the first TL peak and valley (as shown in Figure 4(b)). Figure 4(c) exhibits the transmission loss varying with the locations of the frame masses. The frame widths for three cases remain the same. The distances from the center for Frame I, Frame II, and Frame III are $2.14 \mathrm{~mm}, 3.85 \mathrm{~mm}$, and $5.56 \mathrm{~mm}$, respectively. As the frame moves away from the center, a notable increase in the first TL peak and valley frequencies is observed. The reason is possibly that different frame mass locations result in different eigenmodes of the membrane-frame structure. The characteristic frequencies of the first resonance and TL peak varying with the location of the frame mass are presented in Figure 5. It seems that the first TL peak and resonance frequencies are almost proportional to the mass location which is measured from the membrane center. Also, it is seen that the former rising rate is higher than the latter.

The schematics of the stacked membrane-central-mass structure and stacked membrane-frame structure are displayed in Figures 6(a) and 6(b), respectively. Four different mass magnitudes are considered: $0.08 \mathrm{~g}, 0.16 \mathrm{~g}, 0.24 \mathrm{~g}$, and $0.32 \mathrm{~g}$. Figure 7 shows the comparison of sound transmission of the stacked structure, obtained by FEA analysis, with that of four single-celled structures, obtained by analytical models. It is seen that the TL peaks and valley frequencies of the stacked structure coincide with the ones of single-celled structures. In other words, the characteristic frequencies of the series-type structure can be precisely predicted by singlelayer structures. It is also seen that the width of frequency band in which sound wave cannot propagate is effectively enlarged. Compared with the results shown in Figures 7(a) and 7(b), it seems that the acoustic performances of two stacked structures present a similar behavior. Moreover, more frequency bands due to the periodicity of the structure are created in both cases. Figure 8 exhibits the effects of air spacing on sound transmission of two structures. It is evident that air spacing does affect the frequency band caused by the periodic assembly but has no effect on the TL peak and valley frequencies, caused by resonance and antiresonance of the local resonator. With larger air spacing, the band width becomes wider and the beginning frequency of the band moves toward lower frequency regime. Figure 9 depicts two sketches of the array-type structures. Two unit cells are considered and shown in Figures 9(a) and 9(b), respectively, a membrane with a central mass and the one with a frame mass. The results show that a multipeak TL profile can be created by using different masses at adjacent cells. Sound transmission of the array-type structure and four single-celled structures are compared and displayed in Figure 10. From the results of Figures 10(a) and 10(b), it is seen that the TL valleys for four-celled array correspondingly match the ones for singlecelled structures. In other words, the resonances of the local 
TABLE 2: Properties of frame-shaped mass inclusions.

\begin{tabular}{|c|c|c|c|c|c|c|}
\hline Configuration & Central mass (g) & Frame I (g) & Frame II (g) & $\begin{array}{c}\text { Distance from the } \\
\text { center: Frame I } \\
(\mathrm{mm})\end{array}$ & $\begin{array}{c}\text { Distance from the } \\
\text { center: Frame II } \\
(\mathrm{mm})\end{array}$ & $\begin{array}{l}\text { Frames I and II } \\
\text { width }(\mathrm{mm})\end{array}$ \\
\hline Model I & 0.32 & - & - & - & - & - \\
\hline Model II & - & 0.32 & - & 2.14 & - & 0.856 \\
\hline Model III & 0.32 & 0.32 & - & 2.14 & - & 0.856 \\
\hline Model IV & - & 0.32 & 0.32 & 2.14 & 3.85 & 0.856 \\
\hline
\end{tabular}

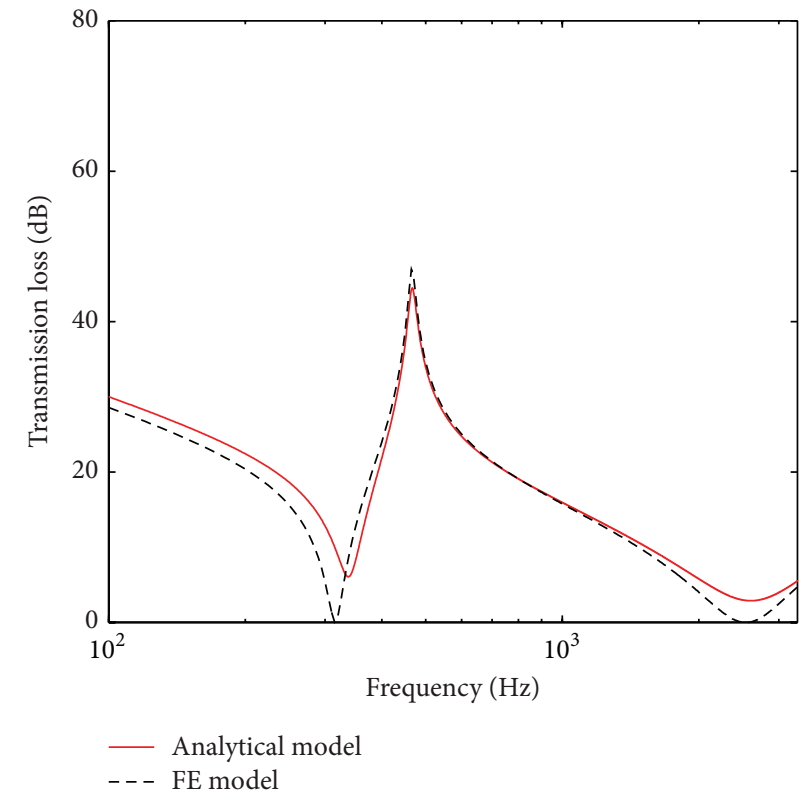

(a)

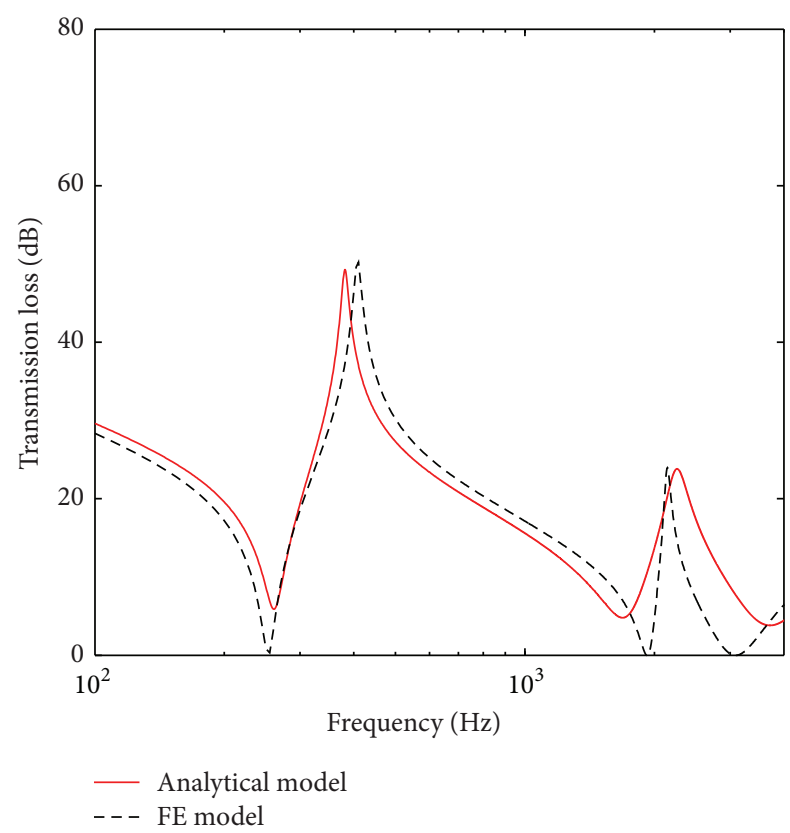

(c)

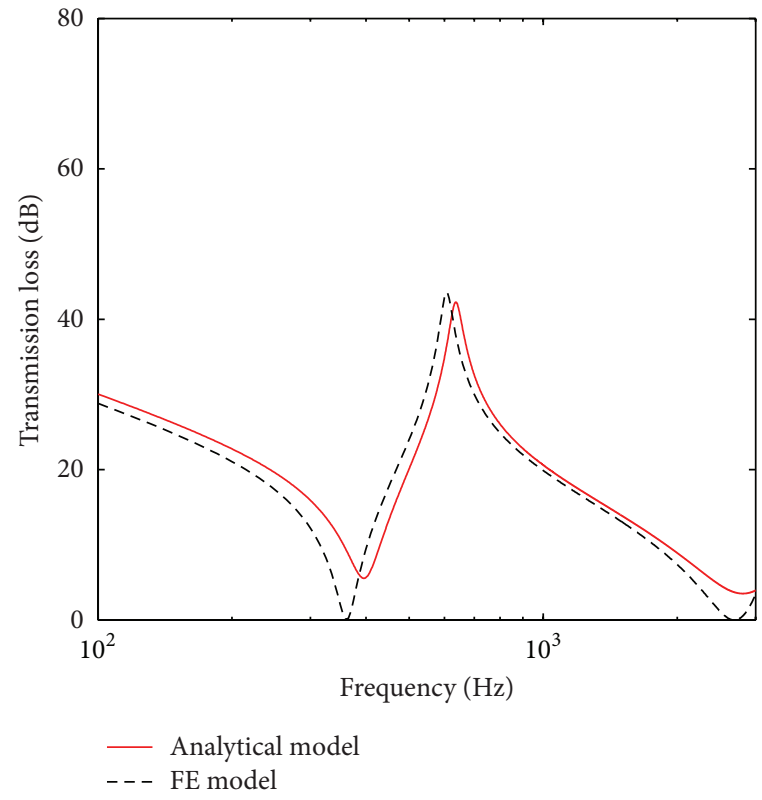

(b)

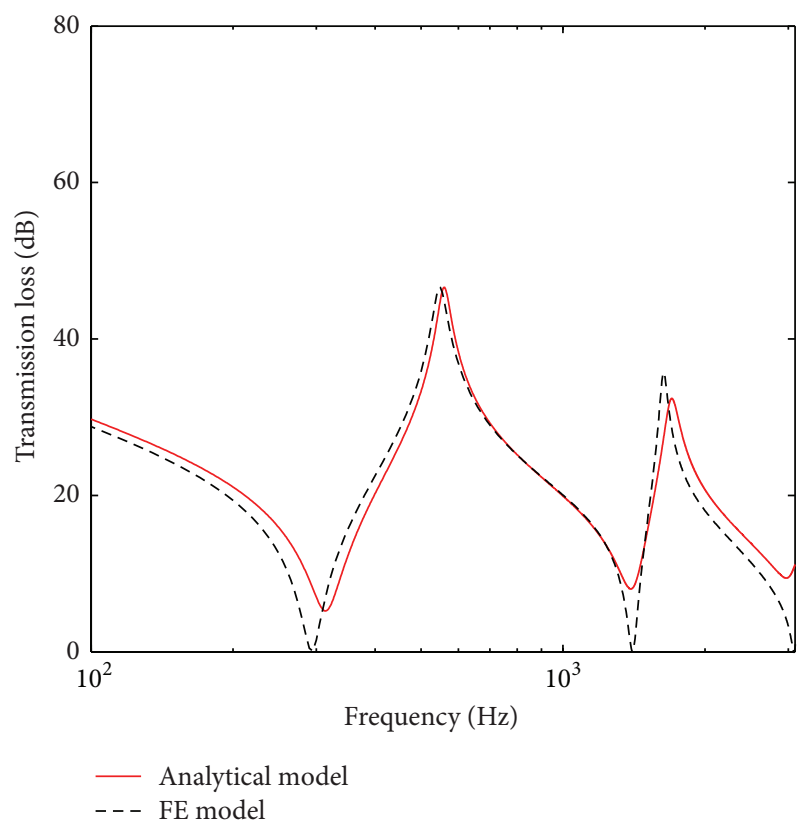

(d)

Figure 2: Transmission loss of (a) Model I, (b) Model II, (c) Model III, and (d) Model IV. 


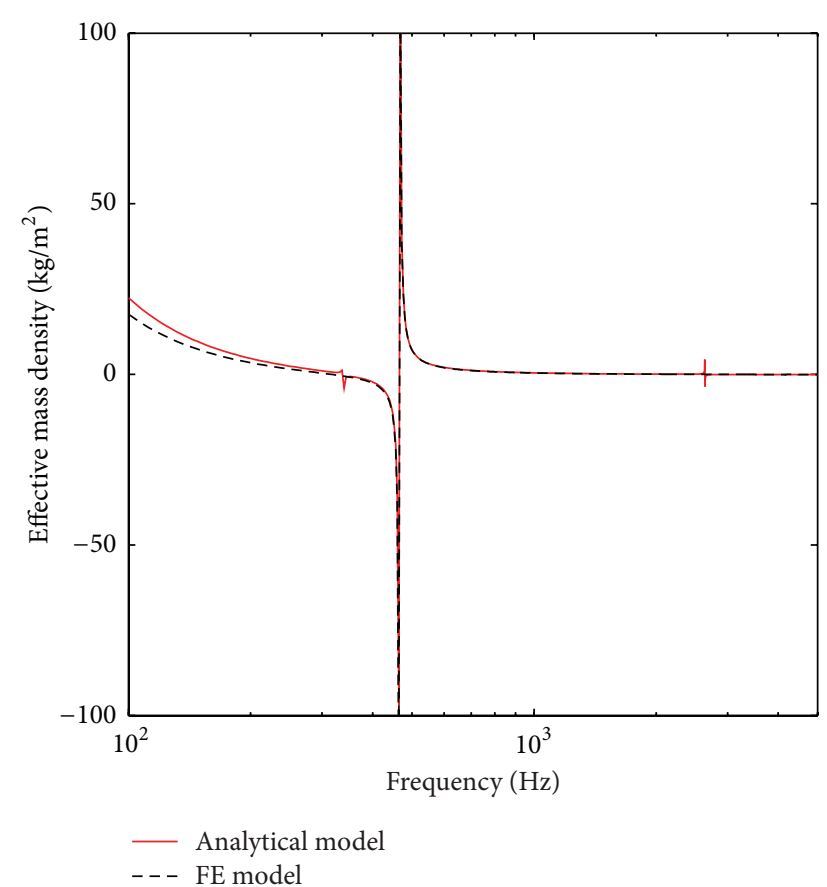

(a)

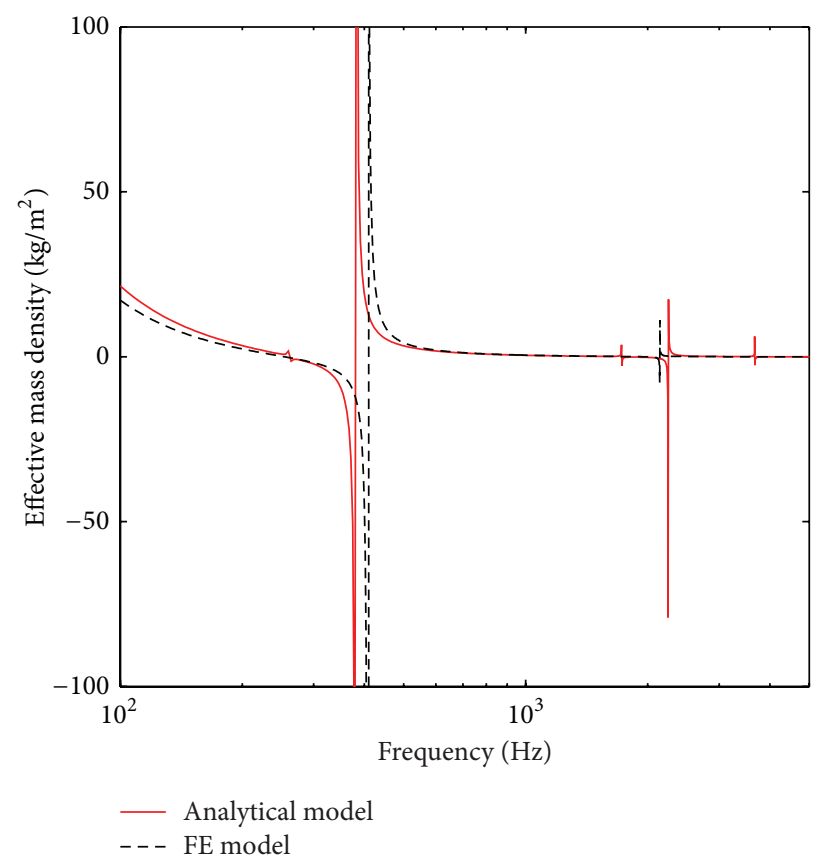

(c)

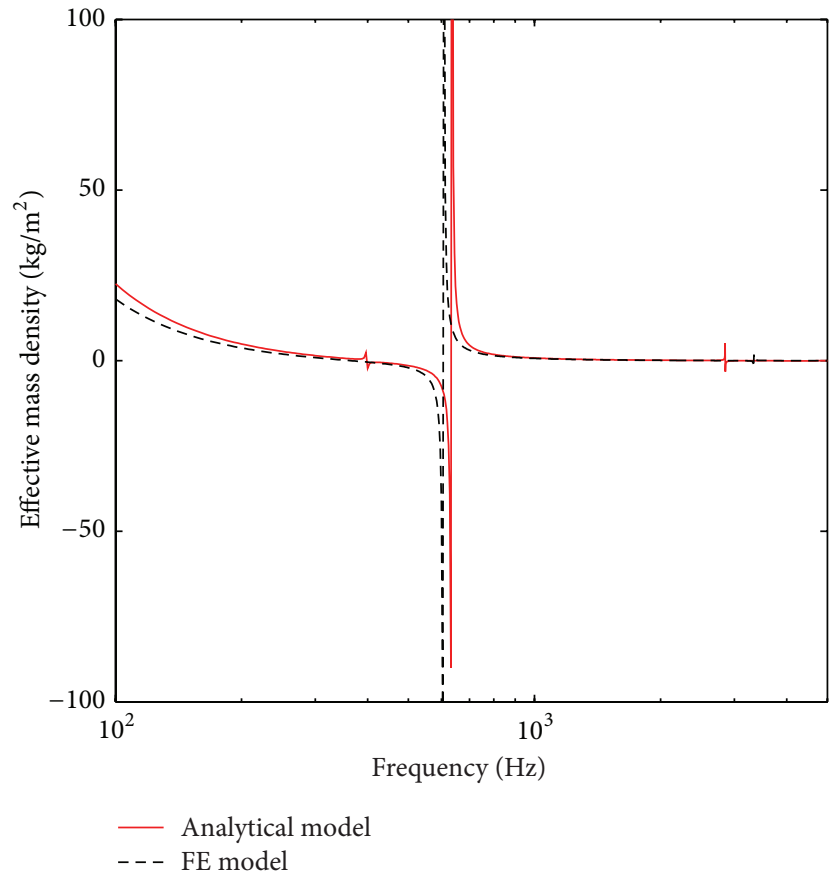

(b)

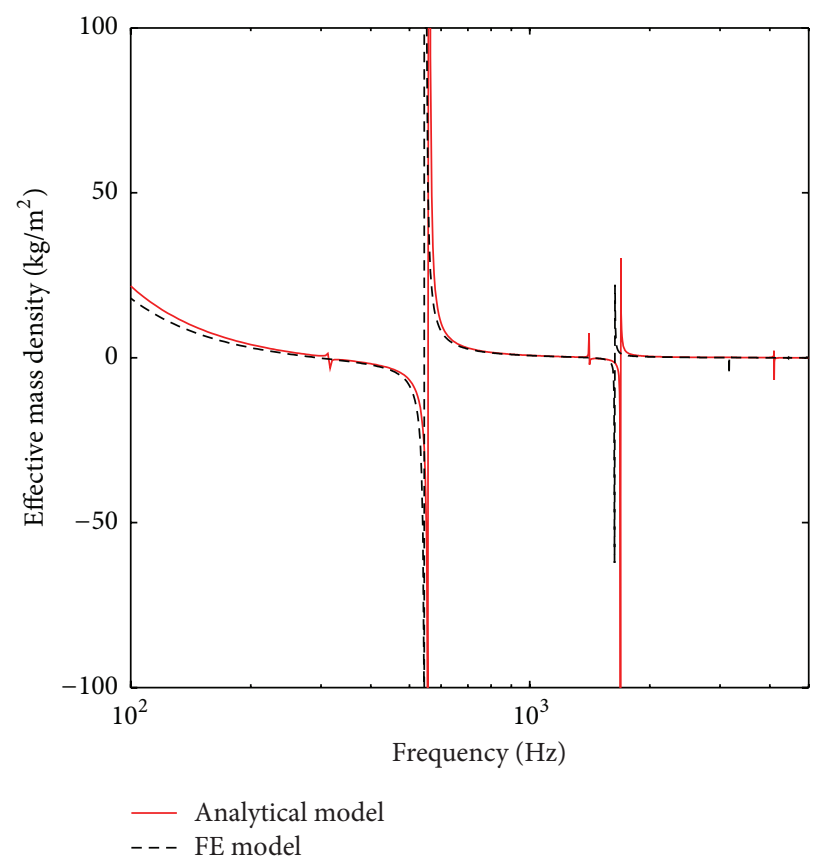

(d)

Figure 3: Dynamic effective mass of (a) Model I, (b) Model II, (c) Model III, and (d) Model IV. 


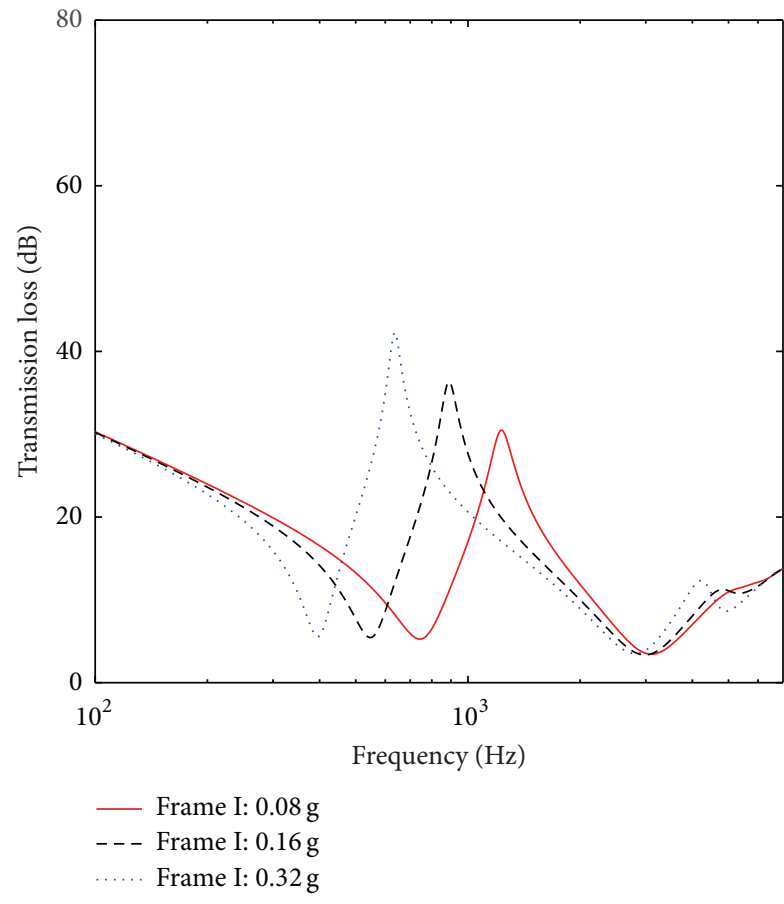

(a)

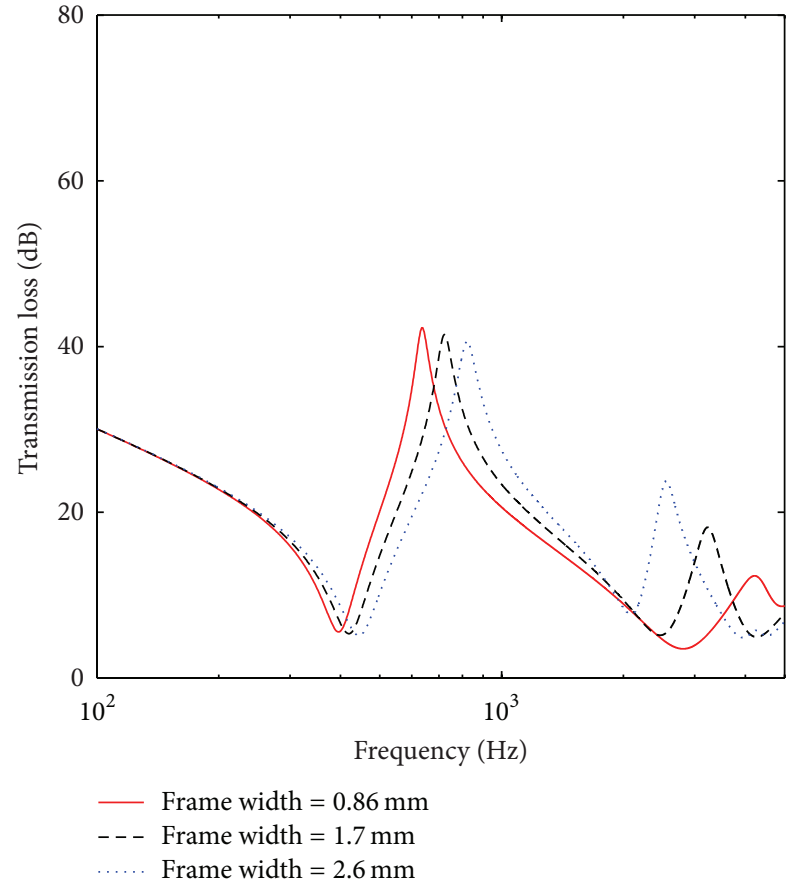

(b)

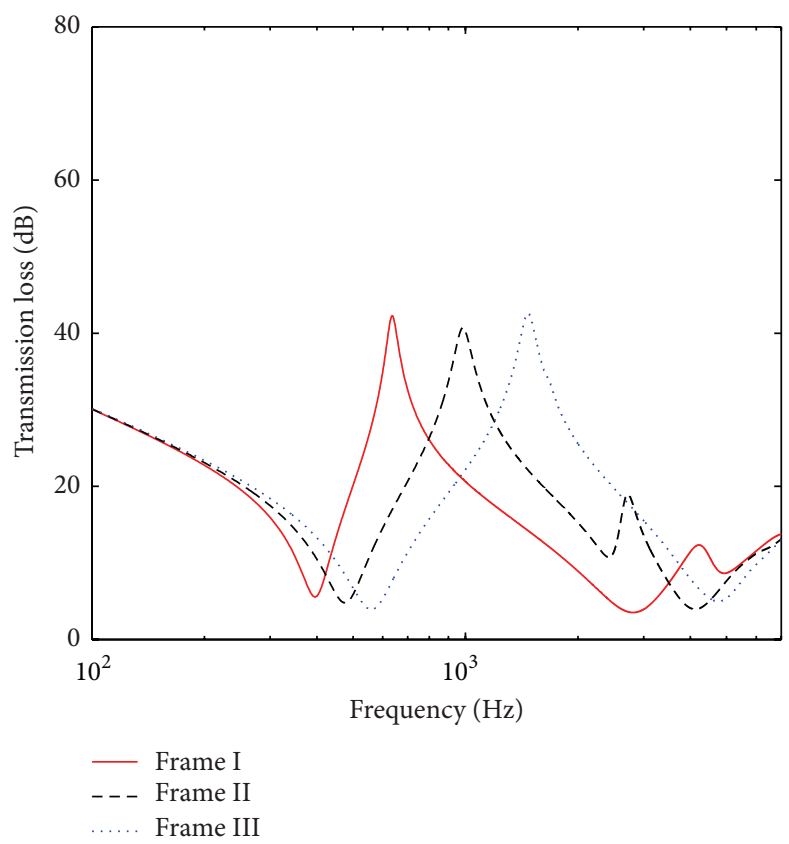

(c)

FIGURE 4: Transmission loss of membrane-frame structure with varying (a) frame mass, (b) frame width, and (c) frame location.

resonators do not depend on the cell arrangement whereas the antiresonance frequencies are affected. As expected, series-type structures can produce stronger attenuation in sound wave than array-type structures and single-celled structures.

\section{Conclusions}

This study addresses the acoustic behavior of thin membranes with square frame-shaped masses. Analytical results are consistent with FE results in transmission loss and effective mass. 


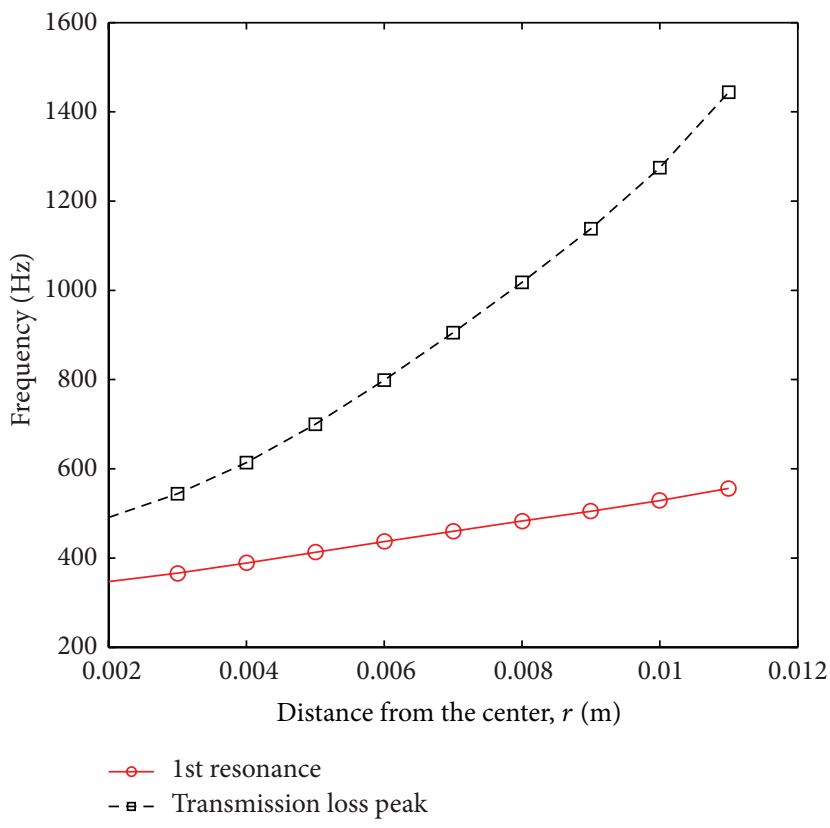

FIGURE 5: The dependence of the first TL peak and TL valley upon the mass location.
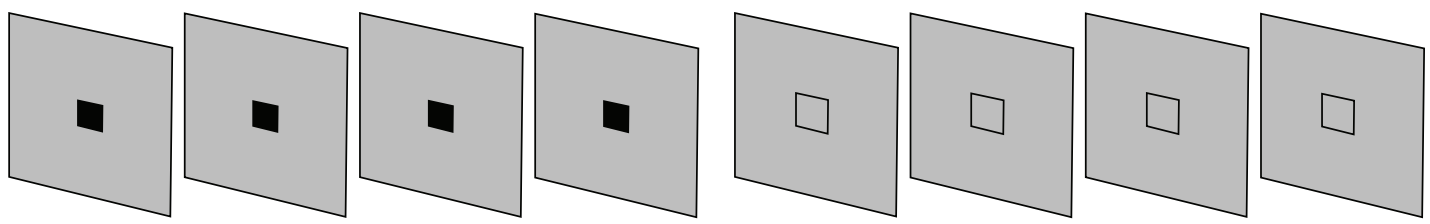

(a)

(b)

FIgURE 6: Schematics of the structures stacked in series with (a) membrane-central-mass units and (b) membrane-frame units.

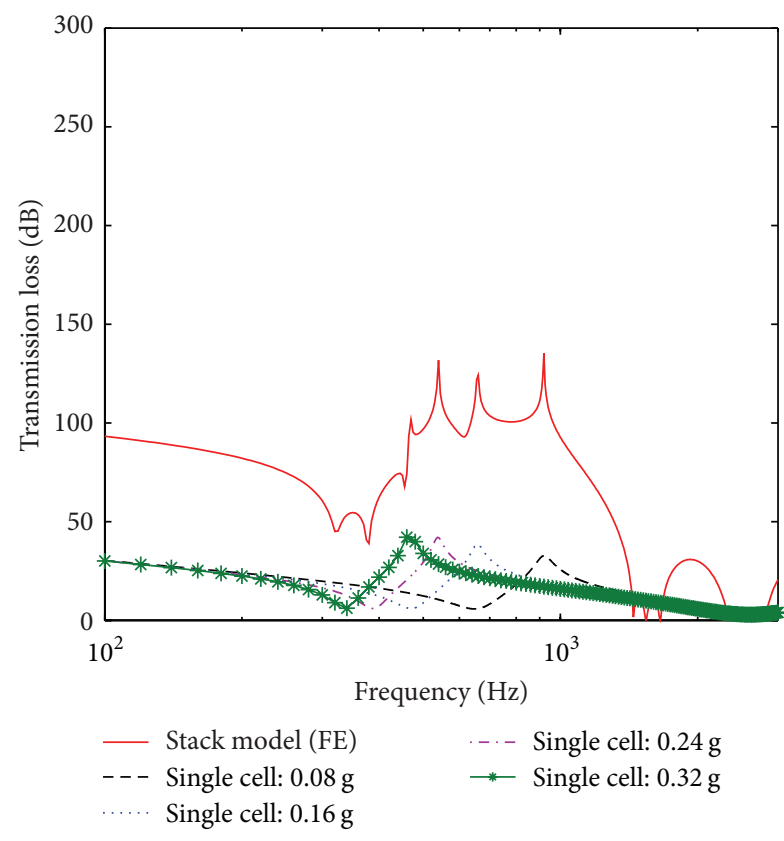

(a)

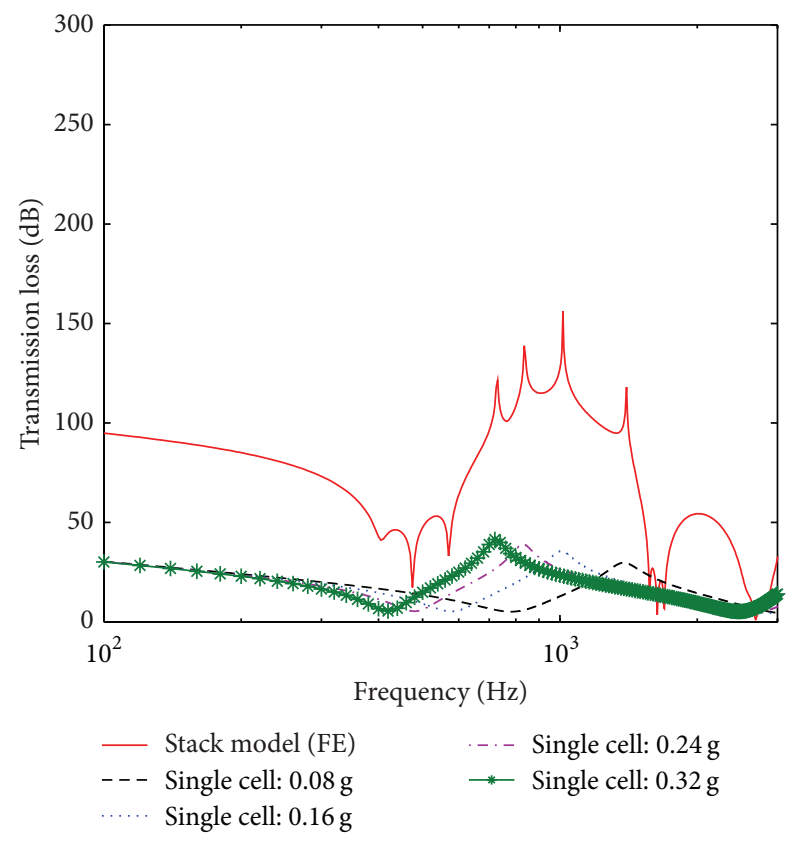

(b)

Figure 7: (a) Comparison of membrane-central-mass structures stacked in series with four single-celled structures and (b) comparison of membrane-frame structures stacked in series with four single-celled structures. 


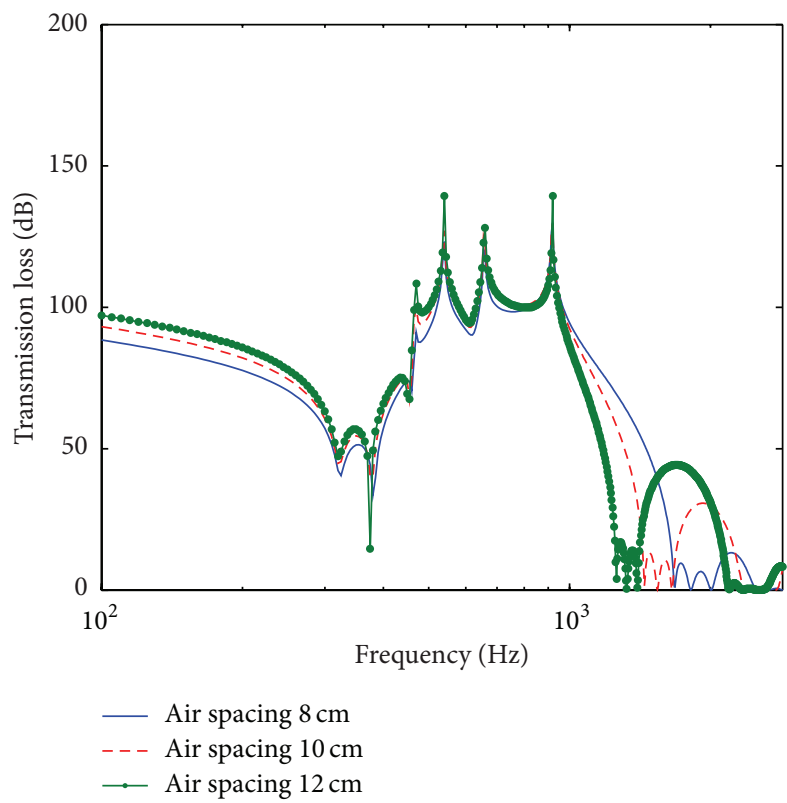

(a)

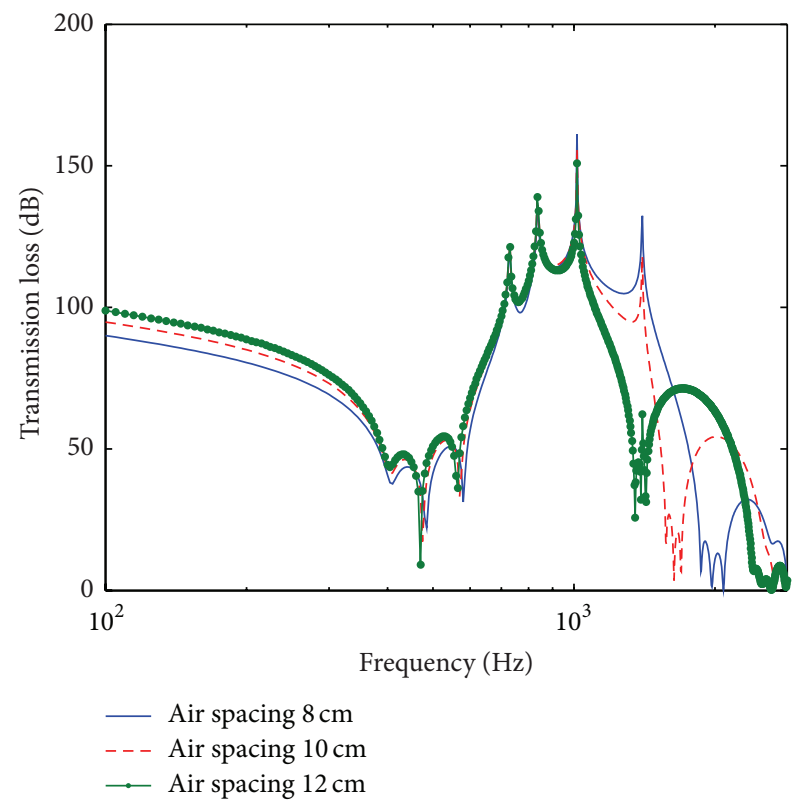

(b)

Figure 8: Effect of air spacing on sound transmission for (a) stacked membrane-central-mass structure and (b) stacked membrane-frame structure.

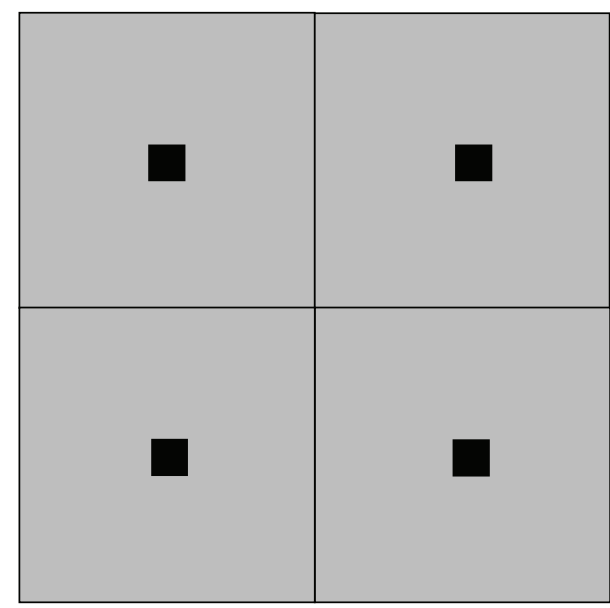

(a)

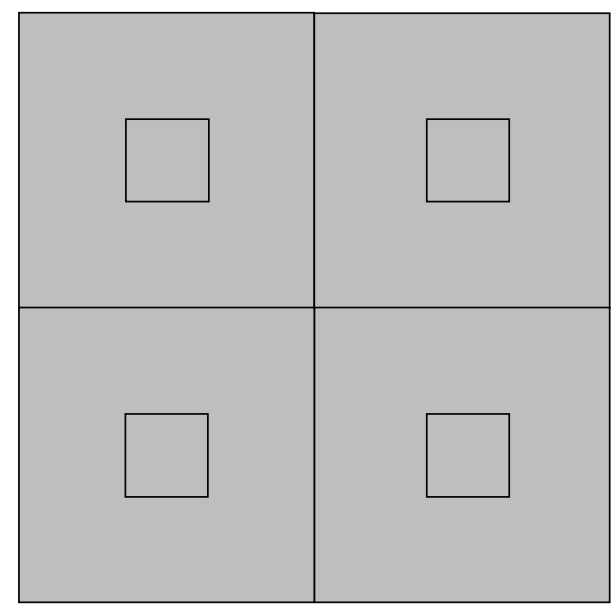

(b)

FIGURE 9: Schematics of the structures arranged in array with (a) membrane-central-mass units and (b) membrane-frame units.

The results indicate that a multipeak TL profile can be created by adding more frame masses in the membrane. Frequencies where negative effective mass occurs coincide with the TL peak frequencies. The TL peak and valley frequencies can be tailored by altering the geometrical and material properties of the frame. Two types of structure arrangements, a seriestype structure and an array-type structure, are also evaluated and compared with single-celled structures. It is found that structures stacked in series can produce a frequency band with wide bandwidth and enhance attenuation in sound wave.

\section{Competing Interests}

The authors declare that they have no competing interests.

\section{Acknowledgments}

The authors would like to thank Dr. Y. T. Chiu and Dr. T. C. Lu from Industrial Technology Research Institute for their constructive comments. This work was supported by the Ministry of Science and Technology of Taiwan under Grant MOST 103-2221-E-006-032 and in part by the Headquarters 


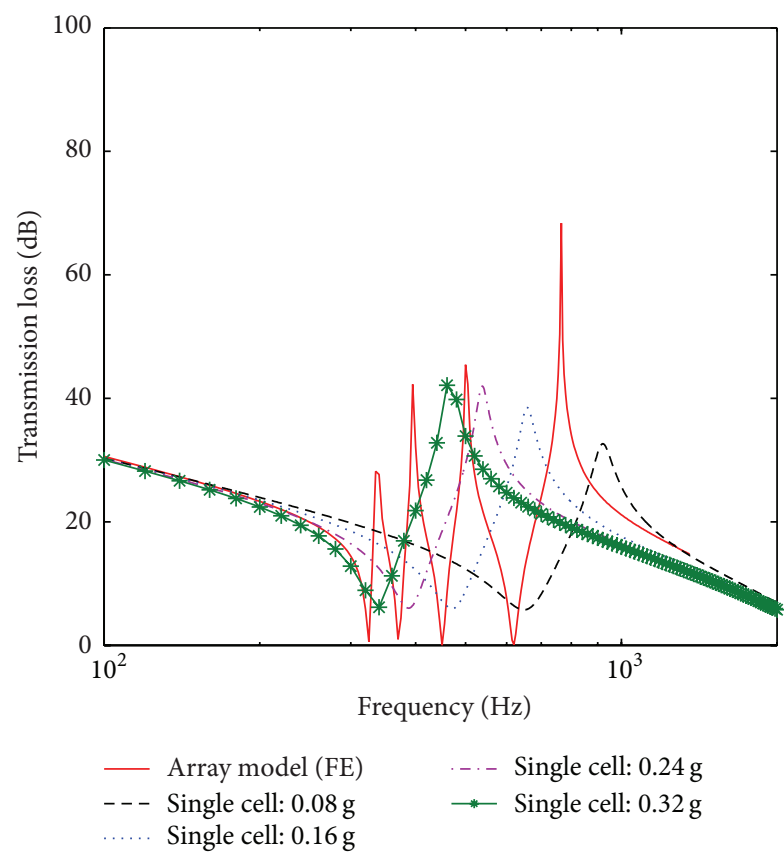

(a)

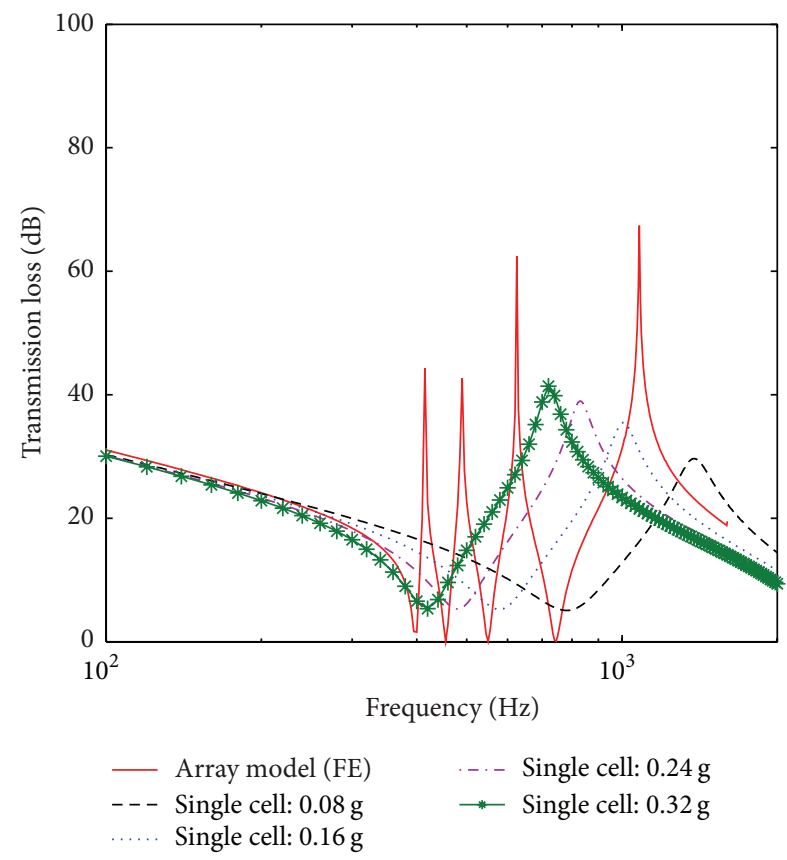

(b)

FIGURE 10: (a) Comparison of membrane-central-mass structures arranged in array with four single-celled structures and (b) comparison of membrane-frame structures arranged in array with four single-celled structures.

of University Advancement at the National Cheng Kung University, which is sponsored by the Ministry of Education, Taiwan.

\section{References}

[1] J. S. Bolton, N.-M. Shiau, and Y. J. Kang, "Sound transmission through multi-panel structures lined with elastic porous materials," Journal of Sound and Vibration, vol. 191, no. 3, pp. 317-347, 1996.

[2] S. A. Lane, S. Griffin, and R. E. Richard, "Fairing noise mitigation using passive vibroacoustic attenuation devices," Journal of Spacecraft and Rockets, vol. 43, no. 1, pp. 31-44, 2006.

[3] D. Y. Maa, "Theory and design of microperforated panel soundabsorbing constructions," Scientia Sinica, vol. 18, pp. 55-71, 1975.

[4] M. R. F. Kidner, C. R. Fuller, and B. Gardner, "Increase in transmission loss of single panels by addition of mass inclusions to a poro-elastic layer: experimental investigation," Journal of Sound and Vibration, vol. 294, no. 3, pp. 466-472, 2006.

[5] K. Idrisi, M. E. Johnson, A. Toso, and J. P. Carneal, "Increase in transmission loss of a double panel system by addition of mass inclusions to a poro-elastic layer: a comparison between theory and experiment," Journal of Sound and Vibration, vol. 323, no. 1-2, pp. 51-66, 2009.

[6] C. J. Naify, C. Huang, M. Sneddon, and S. Nutt, "Transmission loss of honeycomb sandwich structures with attached gas layers," Applied Acoustics, vol. 72, no. 2-3, pp. 71-77, 2011.

[7] S. Yao, X. Zhou, and G. Hu, "Experimental study on negative effective mass in a 1D mass-spring system," New Journal of Physics, vol. 10, Article ID 043020, 2008.
[8] H. H. Huang and C. T. Sun, "Wave attenuation mechanism in an acoustic metamaterial with negative effective mass density," New Journal of Physics, vol. 11, Article ID 013003, 2009.

[9] H. H. Huang, C. T. Sun, and G. L. Huang, "On the negative effective mass density in acoustic metamaterials," International Journal of Engineering Science, vol. 47, no. 4, pp. 610-617, 2009.

[10] S. Yao, X. Zhou, and G. Hu, "Investigation of the negative-mass behaviors occurring below a cut-off frequency," New Journal of Physics, vol. 12, Article ID 103025, 2010.

[11] H. H. Huang and C. T. Sun, "Continuum modeling of a composite material with internal resonators," Mechanics of Materials, vol. 46, pp. 1-10, 2012.

[12] R. U. Ahmed and S. Banerjee, "Wave propagation in metamaterial using multiscale resonators by creating local anisotropy," International Journal of Modern Engineering, vol. 13, no. 2, pp. 51-59, 2013.

[13] Z. Yang, J. Mei, M. Yang, N. H. Chan, and P. Sheng, "Membranetype acoustic metamaterial with negative dynamic mass," Physical Review Letters, vol. 101, no. 20, Article ID 204301, 2008.

[14] C. J. Naify, C.-M. Chang, G. McKnight, and S. Nutt, "Transmission loss and dynamic response of membrane-type locally resonant acoustic metamaterials," Journal of Applied Physics, vol. 108, no. 11, Article ID 114905, 2010.

[15] Z. Yang, H. M. Dai, N. H. Chan, G. C. Ma, and P. Sheng, "Acoustic metamaterial panels for sound attenuation in the 50$1000 \mathrm{~Hz}$ regime," Applied Physics Letters, vol. 96, no. 4, Article ID 041906, 2010.

[16] C. J. Naify, C.-M. Chang, G. McKnight, F. Scheulen, and S. Nutt, "Membrane-type metamaterials: transmission loss of multicelled arrays," Journal of Applied Physics, vol. 109, no. 10, Article ID 104902, 2011.

[17] Y. Zhang, J. Wen, H. Zhao, D. Yu, L. Cai, and X. Wen, "Sound insulation property of membrane-type acoustic metamaterials 
carrying different masses at adjacent cells," Journal of Applied Physics, vol. 114, no. 6, Article ID 063515, 2013.

[18] C. J. Naify, C.-M. Chang, G. McKnight, and S. R. Nutt, "Scaling of membrane-type locally resonant acoustic metamaterial arrays," The Journal of the Acoustical Society of America, vol. 132, no. 4, pp. 2784-2792, 2012.

[19] C. J. Naify, C.-M. Chang, G. McKnight, and S. Nutt, “Transmission loss of membrane-type acoustic metamaterials with coaxial ring masses," Journal of Applied Physics, vol. 110, no. 12, Article ID 124903, 2011.

[20] Y. Zhang, J. Wen, Y. Xiao, X. Wen, and J. Wang, “Theoretical investigation of the sound attenuation of membrane-type acoustic metamaterials," Physics Letters A, vol. 376, no. 17, pp. 1489-1494, 2012.

[21] S. Varanasi, J. S. Bolton, T. H. Siegmund, and R. J. Cipra, “The low frequency performance of metamaterial barriers based on cellular structures," Applied Acoustics, vol. 74, no. 4, pp. 485495, 2013.

[22] Y. Y. Chen, G. L. Huang, X. M. Zhou, G. K. Hu, and C.-T. Sun, "Analytical coupled vibroacoustic modeling of membrane-type acoustic metamaterials: membrane model," The Journal of the Acoustical Society of America, vol. 136, no. 3, pp. 969-979, 2014.

[23] M. M. Sigalas and E. N. Economou, "Elastic and acoustic wave band structure," Journal of Sound and Vibration, vol. 158, no. 2, pp. 377-382, 1992.

[24] M. S. Kushwaha, P. Halevi, L. Dobrzynski, and B. DjafariRouhani, "Acoustic band structure of periodic elastic composites," Physical Review Letters, vol. 71, no. 13, pp. 2022-2025, 1993.

[25] Z. Liu, C. T. Chan, and P. Sheng, "Analytic model of phononic crystals with local resonances," Physical Review B, vol. 71, no. 1, Article ID 014103, 2005.

[26] M. Oudich, Y. Li, B. M. Assouar, and Z. Hou, "A sonic band gap based on the locally resonant phononic plates with stubs," New Journal of Physics, vol. 12, Article ID 083049, 2010.

[27] J.-C. Hsu, "Local resonances-induced low-frequency band gaps in two-dimensional phononic crystal slabs with periodic stepped resonators," Journal of Physics D: Applied Physics, vol. 44, no. 5, Article ID 055401, 2011.

[28] S. Banerjee and R. U. Ahmed, "Phonon confinement using spirally designed elastic resonators in discrete continuum," International Journal of Materials Science and Applications, vol. 3, no. 1, pp. 6-13, 2014.

[29] S. H. Lee, C. M. Park, Y. M. Seo, Z. G. Wang, and C. K. Kim, "Acoustic metamaterial with negative modulus," Journal of Physics Condensed Matter, vol. 21, no. 17, Article ID 175704, 2009.

[30] S. H. Lee, C. M. Park, Y. M. Seo, Z. G. Wang, and C. K. Kim, "Acoustic metamaterial with negative density," Physics Letters A, vol. 373, no. 48, pp. 4464-4469, 2009.

[31] Z. Qian, Y. Fu, P. Yu et al., "A new method for calculating noise reduction of sandwich structures based on modal testing," in Proceedings of the 21st International Congress on Sound and Vibration, pp. 1-8, Beijing, China, July 2014.

[32] P. E. Wellstead, Introduction to Physical System Modelling, Academic Press, London, UK, 1979.

[33] F. Fahy and P. Gardonio, Sound and Structural Vibration: Radiation, Transmission and Response, Academic Press, Orlando, Fla, USA, 1985.

[34] O. Kopmaz and S. Telli, "Free vibrations of a rectangular plate carrying a distributed mass," Journal of Sound and Vibration, vol. 251, no. 1, pp. 39-57, 2002.
[35] M. Mukhopadhyay, Vibrations, Dynamics and Structural Systems, A. A. Balkema Publishers, Brookfield, Vt, USA, 2000. 


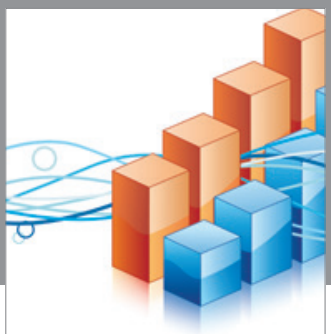

Advances in

Operations Research

vatem alat4

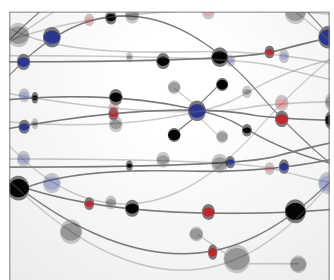

\section{The Scientific} World Journal
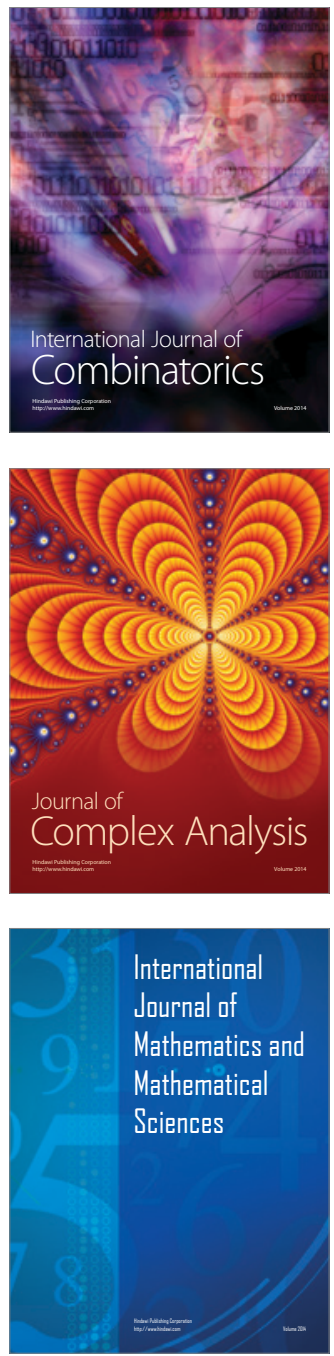
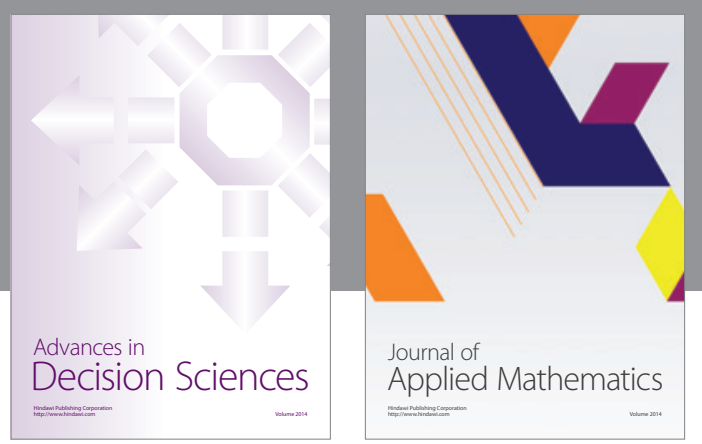

Algebra

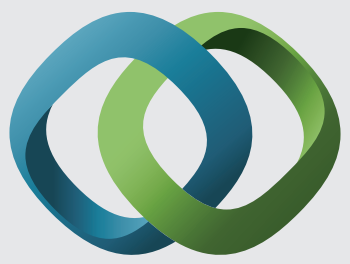

\section{Hindawi}

Submit your manuscripts at

http://www.hindawi.com
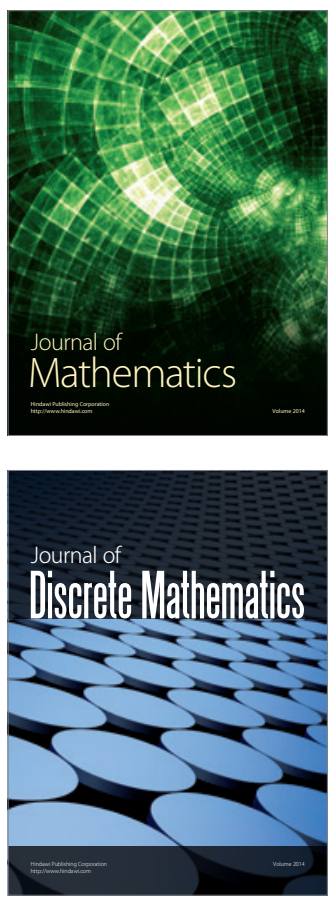

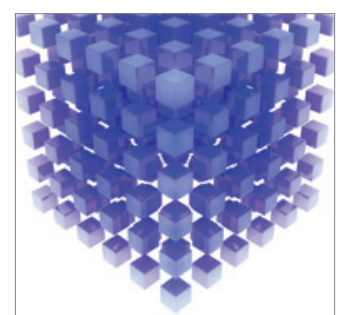

Mathematical Problems in Engineering
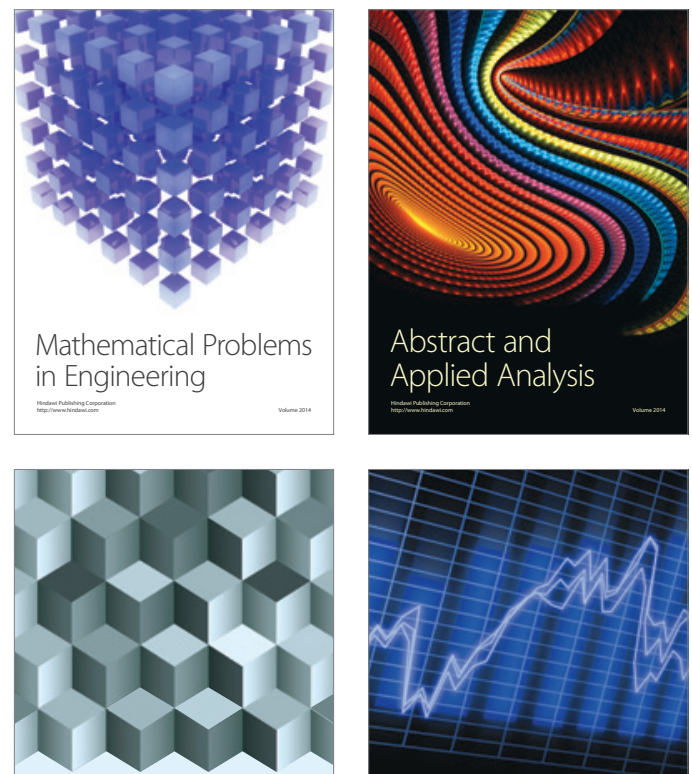

Journal of

Function Spaces

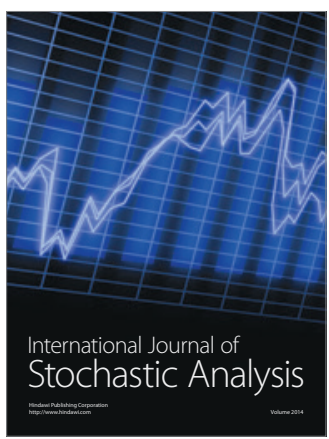

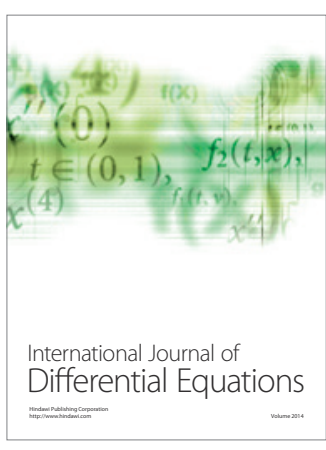
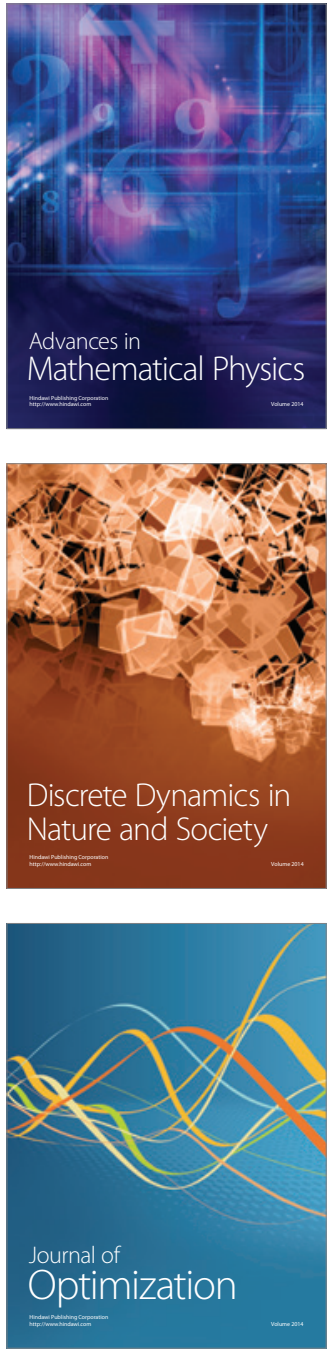